\section{Does Post-Call Syndrome Exist, and Is It Related to Physician Burnout?}

To The Editor: In unstructured, day-to-day conversations on the wards, fellow house officers in several departments have reported to me that they have experienced impaired concentration, hyperphagia with food type-specific cravings, frequent diuresis, irritability, increased startle response, and thermal dysregulation over the course of a post-call day.

One research group demonstrated that approximately $50 \%$ of post-call residents experienced a fibromyalgia-like syndrome (characterized by headache, stiffness, fatigue, and memory impairment) as compared with $13 \%$ of precall residents (1). Research on sleep-loss and fatigue in residency training (reviewed by Veasey, et al. (2)) has demonstrated impairment in cognitive performance, vigilance, and clinical tasks (e.g., serial calculations, TrailMaking Test, and ECG interpretation) after acute sleep deprivation.

The post-call syndrome symptoms extend beyond the symptoms of sleep deprivation, suggesting that the combined effects of sleep deprivation and acute or chronic anxiety may trigger these symptoms. Several physicians (faculty and house staff) briefly debated the origin and validity of the post-call syndrome in the pediatric literature in $1996(3,4)$, and ultimately determined that some house officers experienced a self-limited syndrome. Although anecdotal reports and one research study suggest that a syndrome may exist, further studies of post-call house officers are needed to confirm that a syndrome exists.

Burnout is a well-described and frequently-studied syndrome, with three symptom domains: 1) emotional ex- haustion; 2) depersonalization and cynicism; and 3) feelings of inefficacy (5). Thomas (5) described three possible factors (work characteristics, resident demographics, and personality characteristics) associated with the development of burnout in resident physicians. For instance, the work characteristics of time-demands, lack of control, disorganized work environment, and interpersonal conflicts were associated with burnout and judged by residents to be stressful. Given that all residents have on-call responsibilities, and that the above work-characteristic factors are commonly encountered during on-call duty (possibly contributing to the development of post-call syndrome), it would be important to determine whether the experience of a self-limited post-call syndrome is related to (or predicts) the development of burnout in resident physicians.

Joseph M. Cerimele, M.D.

Dept. of Psychiatry

Mt. Sinai School of Medicine

New York, NY

\section{References}

1. Borham A, Taha R, Griffin F, et al: Post-call residents manifest a fibromyalgia-like syndrome. Abstract presented at: 70th Annual Scientific Meeting of the American College of Rheumatology; Nov 6th-11th, 2007; Boston, MA

2. Veasey S, Rosen R, Barzansky B, et al: Sleep loss and fatigue in residency training: a reappraisal. JAMA 2002; 288:11161124

3. Bergman AB: The post-call syndrome. Arch Pediatr Adolesc Med 1996; 150:329

4. Fiala S: Post-call syndrome. Arch Pediatr Adolesc Med 1996; 150:1220

5. Thomas NK: Resident burnout. JAMA 2004; 292:28802889 